\title{
Estimation of the water-oil-gas relative permeability curve from immiscible WAG coreflood experiments using the cubic B-spline model
}

\author{
Dai-Gang Wang ${ }^{1,2} \cdot$ Yong-Le Hu${ }^{1} \cdot$ Jing-Jing $\mathrm{Sun}^{3} \cdot$ Yong $\mathrm{Li}^{1}$
}

Received: 10 September 2015/Published online: 30 June 2016

(c) The Author(s) 2016. This article is published with open access at Springerlink.com

\begin{abstract}
Immiscible water-alternating-gas (WAG) flooding is an EOR technique that has proven successful for water drive reservoirs due to its ability to improve displacement and sweep efficiency. Nevertheless, considering the complicated phase behavior and various multiphase flow characteristics, gas tends to break through early in production wells in heterogeneous formations because of overriding, fingering, and channeling, which may result in unfavorable recovery performance. On the basis of phase behavior studies, minimum miscibility pressure measurements, and immiscible WAG coreflood experiments, the cubic B-spline model (CBM) was employed to describe the three-phase relative permeability curve. Using the Levenberg-Marquardt algorithm to adjust the vector of unknown model parameters of the CBM sequentially, optimization of production performance including pressure drop, water cut, and the cumulative gas-oil ratio was performed. A novel numerical inversion method was established for estimation of the water-oil-gas relative permeability curve during the immiscible WAG process. Based on the quantitative characterization of major recovery mechanisms, the proposed method was validated by interpreting coreflood data of the immiscible WAG experiment. The proposed method is reliable and can meet engineering requirements. It
\end{abstract}

Dai-Gang Wang

wdg@petrochina.com.cn; dgwang@pku.edu.cn

1 Research Institute of Petroleum Exploration \& Development, PetroChina, Beijing 100083, China

2 School of Earth and Space Sciences, Peking University, Beijing 100871, China

3 College of Petroleum Engineering, China University of Petroleum, Qingdao, Shandong 266580, China

Edited by Yan-Hua Sun provides a basic calculation theory for implicit estimation of oil-water-gas relative permeability curve.

Keywords Cubic B-spline model $\cdot$ Immiscible $\cdot$ WAG flooding $\cdot$ Relative permeability $\cdot$ Numerical inversion

\section{Introduction}

The relative permeability curve is essential to describe the complicated multiphase flow characteristics in porous media (Masihi et al. 2011; Chen et al. 2013). In general, water-oil or oil-gas relative permeability data can be obtained from steady- or unsteady-state displacement experiments with core samples. Such experimental data can be interpreted using analytical methods, e.g., the JohnsonBossler-Naumann (JBN) method. However, due to the idealized hypothesis, the precision usually cannot be guaranteed when using analytical methods to calculate the water-oil or oil-gas relative permeability curve. To improve the precision of the estimated result, Sigmund and McCaffery applied a nonlinear regression to the problem of history matching laboratory coreflood data for the first time and proposed a numerical inversion method for the wateroil relative permeability curve (Sigmund and McCaffery 1979). In contrast to the existing analytical methods, when the numerical inversion methods are adopted to interpret laboratory coreflood data, production performance prior to and after water breakthrough can be utilized comprehensively. The estimated result is not only complete but also highly precise (Daoud and Velasquez 2006; Barroeta and Thompson 2010). In recent decades, a variety of numerical inversion methods have been developed to implicitly estimate the relative permeability curve for water-oil or oilgas systems (Chen et al. 2008; Li et al. 2009; Eydinov et al. 
2009; Wang et al. 2010; Wang and Li 2011; Li and Yang 2011; Abdollahzadeh et al. 2011; Zhang and Yang 2013; Xu et al. 2013; Miao et al. 2014).

As planar and vertical reservoir heterogeneity escalates, it is a great challenge to recover the remaining oil from mature waterflooded oilfields which suffer from extremely high water cut and unfavorable recovery performance of original oil in place (Li 2009; Han 2010). Due to the highly scattered and relatively enriched distribution of remaining oil, efficient enhanced oil recovery (EOR) techniques have become imperative. Water-alternating-gas (WAG) injection has been identified as a cost-effective EOR process yielding high recovery in some oilfields (Luo et al. 2013; Salehi et al. 2014; Laochamroonvorapongse et al. 2014; Sheng 2015). Nevertheless, considering the complicated phase behavior and various flow characteristics in heterogeneous formations, gas tends to break through early in production wells due to overriding, fingering, and channeling, which may result in unfavorable recovery performance. So far, few attempts have been made to implicitly estimate water-oil-gas relative permeability curves during immiscible WAG injection. Taking a synthetic reservoir as an example, $\mathrm{Li}$ et al. proposed a numerical inversion method for estimation of the three-phase relative permeability curve using the ensemble Kalman filter algorithm for assisted history matching. However, due to the inherent limitations confronted by the relative permeability representation model, no significant recognitions were achieved (Li et al. 2012; Chen and Reynolds 2015). Using the Levenberg-Marquardt (LM) algorithm for automatic history matching, Hou et al. addressed the optimization of production performance and relative permeability representation models and finally proposed a numerical inversion method for estimation of the radial water-oil relative permeability curve, which attracts great interest by researchers in petroleum engineering (Hou et al. 2012a, b, 2015).

As a result of the above-mentioned problems, this paper presents a novel numerical inversion method for estimation of the water-oil-gas relative permeability curve during immiscible WAG processes. The structure of this paper is organized as follows. In Sect. 2, the formulation and architecture of the relative permeability representation model are presented. Section 3 provides a brief description of the proposed numerical inversion method using the LM based history matching techniques. In Sect. 4, laboratory tests including phase behavior studies, minimum miscibility pressure (MMP) measurement, and immiscible WAG coreflood experiments are conducted to understand the major recovery mechanisms and thus generate accurate fluid properties under reservoir conditions. Finally, the reliability and robustness of the proposed method are validated by interpreting coreflood data of the immiscible
WAG experiment to implicitly estimate the water-oil-gas relative permeability curve.

\section{Relative permeability representation model}

According to whether it is required to assume the shape of the relative permeability curve, there are two main categories in the representation model: the parametric model and the nonparametric model (Kulkarni and Datta-Gupta 2000). The parametric model uses explicit equations to generate the two- or three-phase relative permeability curve, assuming that the relative permeability curve fits into the shape of a certain type of the functional model (e.g., the power law model). Nevertheless, the number of degrees of freedom of the parametric model is not enough for all types of relative permeability curves for actual reservoirs. Due to its simplicity, the power law model is widely used (Lee and Seinfeld 1987; Reynolds et al. 2004). The nonparametric model is far more general and flexible because there is no assumption regarding the shape of the relative permeability curves [e.g., the cubic B-spline model (CBM)], which has the advantage of being able to accurately represent any set of relative permeability curves. Thus far, the nonparametric model most widely used is the CBM (Chen et al. 2008; Eydinov et al. 2009). For this study, the CBM is adopted to describe the water-oil-gas relative permeability curve during the WAG recovery process.

First, the dimensionless fluid saturation is defined as

$S_{\mathrm{wD}}=\frac{S_{\mathrm{w}}-S_{\mathrm{iw}}}{1-S_{\mathrm{iw}}-S_{\text {orw }}}$

$S_{\mathrm{owD}}=1-S_{\mathrm{wD}}$

$S_{\mathrm{gD}}=\frac{S_{\mathrm{g}}-S_{\mathrm{gc}}}{1-S_{\mathrm{iw}}-S_{\mathrm{gc}}-S_{\mathrm{org}}}$

$S_{\mathrm{ogD}}=1-S_{\mathrm{gD}}$,

where $S_{\mathrm{wD}}$ and $S_{\mathrm{owD}}$ are the dimensionless water and oil saturation for the water-oil system, respectively; $S_{\mathrm{gD}}$ and $S_{\mathrm{ogD}}$ are the dimensionless gas and oil saturation for the oil-gas system, respectively; $S_{\mathrm{w}}$ is the water saturation; $S_{\mathrm{iw}}$ is the initial water saturation; $S_{\text {orw }}$ is the residual oil saturation for the water-oil system; $S_{\mathrm{g}}$ is the gas saturation; $S_{\mathrm{gc}}$ is the critical gas saturation; and $S_{\text {org }}$ is the residual oil saturation for the oil-gas system.

The CBM model for the water-oil-gas relative permeability curve is given by

$k_{\mathrm{rp}}\left(S_{p \mathrm{D}}\right)=\sum_{j=-3}^{n-1} C_{j+2}^{p} B_{j+3}\left(S_{p \mathrm{D}}\right), \quad p=\mathrm{w}, \mathrm{ow}, \mathrm{g}, \mathrm{og}$,

where $k_{\mathrm{r} p}$ is the $p$-phase relative permeability at the dimensionless fluid saturation $S_{p \mathrm{D}} ; n$ is the number of the 
controlling knots; $C_{j+2}^{p}$ is the controlling points for the Bspline approximations of the $p$-phase relative permeability curve; and $B_{j, 3}\left(S_{p \mathrm{D}}\right)$ is the basis function for the CBM model. For detail, please refer to de Boor (de Boor 1978).

It should be noted that the traditional B-spline curve is "attached" to the controlling knots but does not normally pass through them. Therefore, to ensure two of its controlling knots $C_{0}^{p}$ and $C_{n}^{p}$ for the $p$-phase relative permeability curve being traversed, two phantom knots $C_{-1}^{p}$ and $C_{n+1}^{p}$ are introduced for each curve to clamp the endpoints of three-phase relative permeability curves. Equation (6) is proposed to describe the correlation:

$C_{-1}^{p}=2 C_{0}^{p}-C_{1}^{p} \quad$ and $\quad C_{n+1}^{p}=2 C_{n}^{p}-C_{n-1}^{p}$.

Since the water-oil relative permeability and oil-gas relative permeability are, respectively, normalized by $K_{\mathrm{o}}\left(S_{\mathrm{iw}}\right)$ and $K_{\mathrm{o}}\left(S_{\mathrm{gc}}\right)$, it leads to $C_{0}^{\mathrm{ow}}=C_{0}^{\mathrm{og}}=1$. Moreover, the endpoints of the fluid saturation $S_{\mathrm{iw}}, S_{\mathrm{orw}}, S_{\mathrm{gc}}$, and $S_{\mathrm{org}}$ are regarded as known values, i.e., $C_{n}^{\mathrm{ow}}=C_{n}^{\mathrm{og}}=C_{0}^{\mathrm{w}}=$ $C_{0}^{\mathrm{g}}=0$. There are $n-1$ parameters to be estimated for the oil relative permeability of the water-oil or oil-gas system, and there are $n$ parameters to be estimated for the water or gas relative permeability. Finally, there are total $4 n-2$ parameters to be estimated for the water-oil-gas system.

To enforce the monotonicity and convexity of the threephase relative permeability curve, a log transformation from the controlling knots to pseudo-controlling knots is carried out. For the water-phase or gas-phase relative permeability curve,

$$
\left\{\begin{array}{l}
x_{1}^{u}=\ln \left(\frac{C_{1}^{u}}{\frac{1}{2}\left(C_{2}^{u}+0\right)-C_{1}^{u}}\right) \\
x_{i}^{u}=\ln \left(\frac{C_{i}^{u}-\left(2 C_{i-1}^{u}-C_{i-2}^{u}\right)}{\frac{1}{2}\left(C_{i+1}^{u}+C_{i-1}^{u}\right)-C_{i}^{u}}\right), 2 \leq i \leq n-1 ; \quad u=\mathrm{w}, \mathrm{g} . \\
x_{n}^{u}=\ln \left(\frac{C_{n}^{u}-\left(2 C_{n-1}^{u}-C_{n-2}^{u}\right)}{1-C_{n}^{u}}\right) .
\end{array}\right.
$$

For the oil-phase relative permeability curve of the water-oil or oil-gas system,

$$
\left\{\begin{array}{l}
y_{1}^{v}=\ln \left(\frac{C_{1}^{v}-\left(2 C_{2}^{v}-C_{3}^{v}\right)}{\frac{1}{2}\left(C_{2}^{v}+1\right)-C_{1}^{v}}\right) \\
y_{i}^{v}=\ln \left(\frac{C_{i}^{v}-\left(2 C_{i+1}^{v}-C_{i+2}^{v}\right)}{\frac{1}{2}\left(C_{i+1}^{v}+C_{i-1}^{v}\right)-C_{i}^{v}}\right), 2 \leq i \leq n-2 ; \quad v=\text { ow }, \text { og. } \\
y_{n-1}^{v}=\ln \left(\frac{C_{n-1}^{v}-0}{\frac{1}{2} C_{n-2}^{v}-C_{n-1}^{v}}\right)
\end{array}\right.
$$

To sum up, the vector $\mathbf{m}$ of unknown model parameters of the CBM can be expressed as

$$
\begin{gathered}
\mathbf{m}=\left[x_{1}^{\mathrm{w}}, x_{2}^{\mathrm{w}}, \ldots, x_{n}^{\mathrm{w}}, y_{1}^{\mathrm{ow}}, y_{2}^{\mathrm{ow}}, \ldots, y_{n-1}^{\mathrm{ow}}, x_{1}^{\mathrm{g}}, x_{2}^{\mathrm{g}}, \ldots, x_{n}^{\mathrm{g}}, y_{1}^{\mathrm{og}},\right. \\
\left.y_{2}^{\mathrm{og}}, \ldots, y_{n-1}^{\mathrm{og}}\right] .
\end{gathered}
$$

With regard to the actual estimation of the three-phase relative permeability curve, the vector $\mathbf{m}$ of unknown model parameters, which is composed of the pseudo-controlling knot vectors ( $\mathbf{x}$ and $\mathbf{y}$ ) mentioned above, is adjusted subsequently using the optimization algorithm. After each iteration, the controlling knot vectors $\left(\mathbf{C}^{u}\right.$ and $\left.\mathbf{C}^{v}\right)$ are calculated by inverse transforming the pseudo-controlling parameters. Then, the water-oil and oil-gas relative permeabilities satisfying the monotonicity and convexity rule are obtained from the cubic B-spline model. For this study, the number of controlling knots $n$ is equal to 7 .

Once the water-oil and oil-gas relative permeabilities are obtained after each iteration, the modified Stone's Model II (Aziz and Settari 1979) is further adopted to calculate the oil relative permeability curve when all three phases are mobile, which takes the form of

$$
\begin{aligned}
K_{\mathrm{ro}}\left(S_{\mathrm{w}}, S_{\mathrm{g}}\right)= & K_{\mathrm{row}}^{0}\left[\left(\frac{K_{\mathrm{row}}\left(S_{\mathrm{w}}\right)}{K_{\mathrm{row}}^{0}}+K_{\mathrm{rw}}\left(S_{\mathrm{w}}\right)\right)\right. \\
& \left.\times\left(\frac{K_{\mathrm{rog}}\left(S_{\mathrm{g}}\right)}{K_{\mathrm{row}}^{0}}+K_{\mathrm{rg}}\left(S_{\mathrm{g}}\right)\right)-\left(K_{\mathrm{rw}}\left(S_{w}\right)+K_{\mathrm{rg}}\left(S_{\mathrm{g}}\right)\right)\right],
\end{aligned}
$$

where $K_{\mathrm{rw}}$ and $K_{\text {row }}$ are the water and oil relative permeability for the water-oil system, respectively; $K_{\text {rg }}$ and $K_{\text {rog }}$ are the gas and oil relative permeability for the oil-gas system, respectively; and $K_{\text {row }}^{0}$ is the oil relative permeability at the connate water saturation (in oil-water flow), and at the critical saturation (in oil-gas flow).

\section{Methodology}

\subsection{Least-squares objective function}

Provided that the predicted production performance is in accordance with the observed values, a least-squares objective function needs to be established for estimation of the water-oil-gas relative permeability curve and can be described as follows:

$O(\mathbf{m})=\frac{1}{2}\left(\mathbf{g}(\mathbf{m})-\mathbf{d}_{\mathrm{obs}}\right)^{\mathrm{T}} \mathbf{C}_{\mathrm{D}}^{-1}\left(\mathbf{g}(\mathbf{m})-\mathbf{d}_{\mathrm{obs}}\right)$,

where $O(\mathbf{m})$ is the least-squares objective function; $\mathbf{m}$ is a $(m \times 1)$ vector of the unknown model parameters; $\mathrm{T}$ is a symbol denoting the transpose of a vector or matrix; $\mathbf{d}_{\mathrm{obs}}$ is a $(n \times 1)$ vector of the observed (or measured) data; $\mathbf{g}(\mathbf{m})$ is a $(n \times 1)$ vector of the predicted data; and $\mathbf{C}_{\mathrm{D}}$ is the $(n \times n)$ covariance matrix. With regard to the actual history 
matching problems, the objective function $O(\mathbf{m})$ is usually nonlinear and the vector of model parameters $\mathbf{m}$ should be confined to a reasonable range according to reservoir conditions. In this study, the pressure drop, water cut, and the cumulative gas-oil ratio are considered as the observed production performance to establish the least-squares objective function.

\subsection{LM algorithm}

The LM algorithm (Oliver and Chen 2011), one of the gradient-based algorithms most widely used, has high computational efficiency and a quick convergence speed. When using the LM algorithm to solve the inverse history matching problems, the smooth transition can be addressed successively between the steepest descent algorithm and the Newton algorithm (Barua et al. 1988). The optimization procedure should satisfy the following principle: if the least-squares objective function is far from the minimum point, the convergence direction should be identical to that of the steepest descent algorithm; if the objective function is close to the minimum point, the convergence direction is the same as that of the Newton algorithm. Optimization of production performance in this paper is performed using the LM algorithm. In addition, a finite difference method is adopted to compute the sensitivity matrix of the leastsquares objective function at the unknown model parameters. The generalized form of the LM algorithm is depicted as Eq. (12):

$\left(\lambda \mathbf{I}+\mathbf{H}\left(\mathbf{m}^{k}\right)\right) \delta \mathbf{m}^{k+1}=-\nabla O\left(\mathbf{m}^{k}\right)$,

where $\mathbf{H}\left(\mathbf{m}^{k}\right)$ is the Hessian matrix for the $k$ th iteration; $\mathbf{I}$ is an $(n \times n)$ identity matrix; $\lambda$ is the damping factor to guarantee the half-positive definitiveness of the Hessian matrix; $O\left(\mathbf{m}^{k}\right)$ is the least-squares objective function for the $k$ th iteration; $\mathbf{m}^{k}$ and $\mathbf{m}^{k+1}$ are, respectively, the vector of unknown model parameters obtained by the $k$ th and $(k+1)$ th iterations, and $\delta \mathbf{m}^{k+1}=\mathbf{m}^{k+1}-\mathbf{m}^{k}$; and $\nabla$ is the Hamiltonian operator.

The following is the specific calculation procedure of using the LM algorithm for automatic history matching. First, input the initial damping factor $\lambda_{0}$. After each iteration, it is necessary to adjust the values of the damping factor. The principle for adjustment is summarized as follows: (1) Calculate the vector of unknown model parameters $\mathbf{m}^{k+1}$. If $O\left(\mathbf{m}^{k+1}\right) \geq O\left(\mathbf{m}^{k}\right)$, the iteration is regarded as a failure, and then $\lambda=\lambda \times 10$. If $O\left(\mathbf{m}^{k+1}\right)<O\left(\mathbf{m}^{k}\right)$, the iteration is regarded as a success, and then $\lambda=\lambda \times 10$. (2) Submit the damping factor $\lambda$ adjusted to Eq. (12) and carry out the next iteration. The iteration described previously is repeated until the termination condition is satisfied.
The termination condition of iteration utilized takes the form of Eq. (13):

$\left|O\left(\mathbf{m}^{k+1}\right)-O\left(\mathbf{m}^{k}\right)\right|<\varepsilon_{1} \quad$ or $\quad$ count $>$ count $_{\max }$,

where $\varepsilon_{1}$ is the convergence precision (fraction); count is the iteration times (integer); and count $_{\max }$ is the maximum iteration times (integer). For this study, $\varepsilon_{1}=10^{-6}$ and count $_{\max }=100$.

\subsection{Procedure of parameter estimation}

The procedure for implicitly estimating the three-phase relative permeability curve using LM based history matching techniques is briefly described as follows: (1) initialize the unknown controlling parameters of the CBM to generate prior knowledge of the three-phase relative permeability curve; (2) implement reservoir simulation using the prior curves to generate the predicted production data; (3) establish a leastsquares objective function to reflect the discrepancy between the predicted and observed values of production performance; and (4) advance the minimization of the least-squares objective function using the LM algorithm to subsequently adjust the unknown controlling parameter vector of the CBM until all the observed production data are assimilated. Finally, the water-oil-gas three-phase relative permeability curve is achieved and evaluated.

\section{Laboratory tests}

Using synthetic core samples, laboratory tests including phase behavior studies, MMP measurements, and immiscible WAG coreflood experiments were conducted to understand the major recovery mechanisms of immiscible WAG injection and thus generate accurate fluid properties under reservoir conditions.

\subsection{Phase behavior studies}

Well product and dissolved gas were collected from a lowpermeability classic sandstone reservoir in the Jidong Oilfield, China. The density and viscosity of the well product were measured to be $0.871 \mathrm{~g} / \mathrm{cm}^{3}$ and $8.477 \mathrm{mPa}$ s at $20{ }^{\circ} \mathrm{C}$ and at atmospheric pressure, respectively. The injection gas with a molar mass of $20.6 \mathrm{~g} / \mathrm{mol}$ and a relative density of 0.71 came from a neighboring reservoir. The compositions of the well product, dissolved gas, and the injection gas are listed in Table 1 . For this study, a synthetic oil sample was prepared from the well product and the dissolved gas according to the initial dissolved gas-oil ratio of $70.58 \mathrm{~m}^{3} / \mathrm{sm}^{3}$.

Single-phase flash and saturated pressure measurements were performed on the synthetic oil sample at the reservoir 
temperature of $120.8{ }^{\circ} \mathrm{C}$. The dissolved gas-oil ratio and the saturated pressure were measured to be $69.0 \mathrm{~m}^{3} / \mathrm{sm}^{3}$ and 14.1 $\mathrm{MPa}$, respectively, which are so close to those determined under the initial reservoir conditions that the synthetic oil sample satisfies the requirement of phase behavior studies.

\subsubsection{Influence of hydrocarbon gas injected on saturated pressure}

The integrated experimental apparatus (Guo et al. 2000) provided by the Ruska Instrument Corporation, United States, was used to understand the influence of hydrocarbon gas injected on saturated pressure at a reservoir temperature of $120.8^{\circ} \mathrm{C}$. This apparatus consisted of a fluid property measurement device and a high-pressure fallingball viscometer. Figure 1 shows the correlation of relative volume with pressure under various mole fractions of hydrocarbon gas injected.

Figure 1 demonstrates that there is a distinct breaking point indicating the saturated pressure, especially when the mole fraction of hydrocarbon gas injected is relatively low. Meanwhile, the fluid phase behavior changed significantly as the experimental pressure dropped. With an increase in the mole fraction of hydrocarbon gas injected, the correlation of relative volume with pressure gradually shifted toward the right accompanied by the disappearance of the breaking point, which indicates that the continuous solution of injected hydrocarbon gas results in an increase in the saturated pressure and a reduction of discrimination between gas-liquid phases to a large extent.

\subsubsection{Influence of hydrocarbon gas injected on fluid properties}

Using the constant composition expansion test, differential liberation test, and the swelling test under the reservoir

Table 1 Compositions of the well product, dissolved gas, and the injection gas

\begin{tabular}{lccc}
\hline Component & \multicolumn{3}{l}{ Composition, wt\% } \\
\cline { 2 - 4 } & Well product & Dissolved gas & Injection gas \\
\hline $\mathrm{CO}_{2}$ & 0.06 & 0.12 & 0.32 \\
$\mathrm{~N}_{2}$ & 0.07 & 0.14 & 0.19 \\
$\mathrm{CH}_{4}$ & 30.67 & 61.79 & 83.62 \\
$\mathrm{C}_{2} \mathrm{H}_{6}$ & 8.76 & 17.64 & 7.64 \\
$\mathrm{C}_{3} \mathrm{H}_{8}$ & 5.96 & 11.98 & 3.78 \\
$i-\mathrm{C}_{4} \mathrm{H}_{10}$ & 0.72 & 1.46 & 0.97 \\
$n-\mathrm{C}_{4} \mathrm{H}_{10}$ & 1.55 & 3.13 & 1.52 \\
$i-\mathrm{C}_{5} \mathrm{H}_{12}$ & 0.27 & 0.54 & 0.66 \\
$n-\mathrm{C}_{5} \mathrm{H}_{12}$ & 0.26 & 0.53 & 0.56 \\
$\mathrm{C}_{6+}$ & 51.69 & 2.67 & 0.74 \\
\hline
\end{tabular}

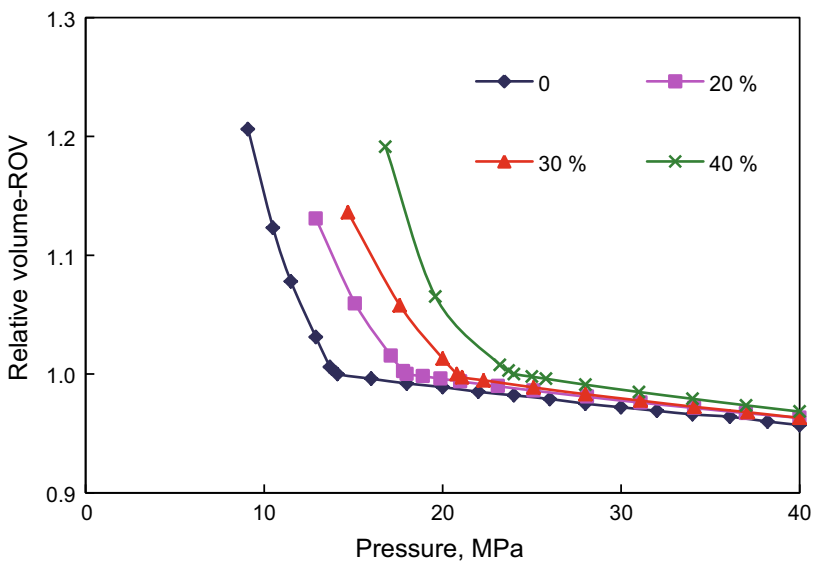

Fig. 1 Correlation of relative volume with pressure under various mole fractions of hydrocarbon gas injected

temperature of $120.8{ }^{\circ} \mathrm{C}$, the influence of various mole fractions of hydrocarbon gas injected on variation of fluid properties was investigated, as presented in Figs. 2 and 3. The results show that, with the escalation of hydrocarbon gas injected, the saturated pressure increased gradually along with a decrease in oil density and viscosity, which shows a closer similarity between gas and liquid phases, and as such better fluid properties will be achieved.

\subsection{MMP measurement}

A long slim-tube displacement experiment was conducted to determine the minimum miscibility pressure (MMP) between the synthetic oil sample and hydrocarbon gas. Generally, if the recovery factor is greater than $80 \%$ when hydrocarbon gas breakthrough occurs or the ultimate oil recovery reaches $90 \%-95 \%$ after 1.2 pore volume (PV) hydrocarbon gas is injected, it is treated as a state of miscibility. The experimental setup was provided by the Ruska Company, United States, and consisted of an

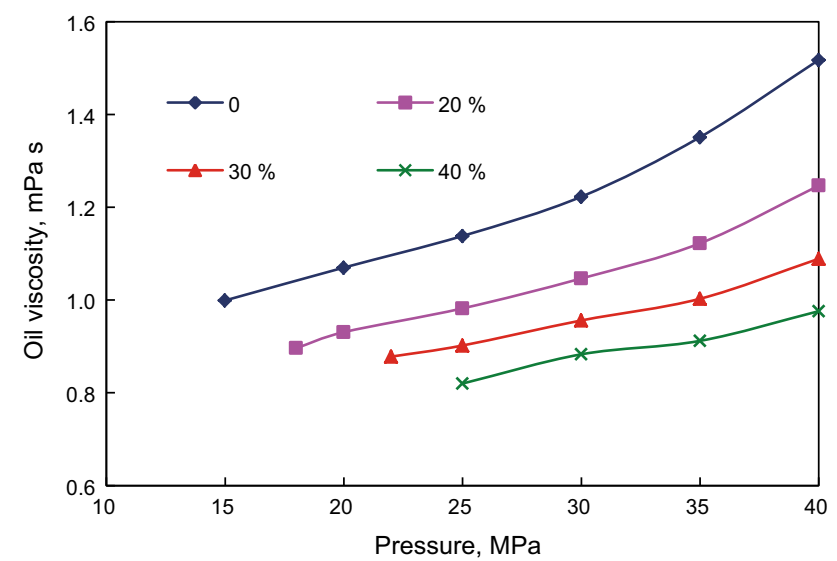

Fig. 2 Variation of oil viscosity with pressure with various mole fractions of hydrocarbon gas injected 


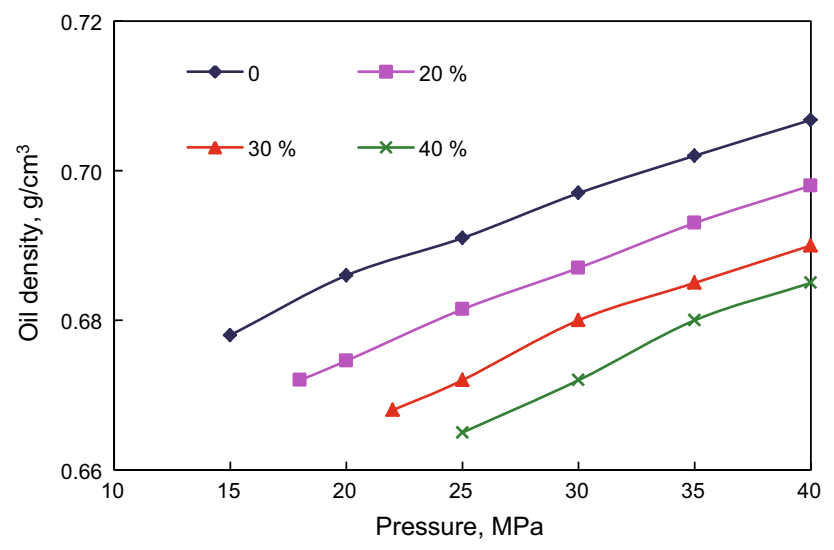

Fig. 3 Variation of oil density with pressure with various mole fractions of hydrocarbon gas injected

injection system with a positive displacement pump, a slim tube, a backpressure regulator, a differential pressure transducer, a temperature-controlling system, a sample collection system, and a gas chromatograph. The long slimtube model was approximately $18 \mathrm{~m}$ in length and $4 \mathrm{~mm}$ in diameter, with a pore volume of $125 \mathrm{~cm}^{3}$ at $20{ }^{\circ} \mathrm{C}$ and at atmospheric pressure.

Prior to displacement, the long slim-tube model was fully saturated with the synthetic oil sample at the reservoir temperature of $120.8{ }^{\circ} \mathrm{C}$ and under the ambient pressure above the bubble point. The experimental pressures were 25.0, 26.6, 30.0, and 33.0 MPa, respectively. The long slim-tube displacement experiments were performed at a constant gas injection rate of $0.167 \mathrm{~cm}^{3} / \mathrm{min}$ until $1.2 \mathrm{PV}$ of hydrocarbon gas was injected. It should be noted that the pressure regulator must be adjusted sequentially during the displacement process in order to retain the ambient pressure close enough to the experimental pressure with its fluctuation range less than $0.05 \mathrm{MPa}$. As shown in Fig. 4, miscibility between the synthetic crude oil and hydrocarbon gas would be achieved as the experimental pressure reached 30.0 MPa. The MMP was further obtained using the interpolation method and its value was $29.0 \mathrm{MPa}$, which is significantly higher than the current reservoir pressure $27.0 \mathrm{MPa}$. That is to say, miscibility cannot be achieved under the current reservoir conditions.

\subsection{Immiscible WAG coreflood experiment}

Core samples were prepared to conduct the immiscible WAG coreflood experiments using a total of 12 representative samples taken from the same low-permeability sandstone reservoir. The physical properties of the actual reservoir core samples are listed in Table 2 . The synthetic core sample was approximately $66.8 \mathrm{~cm}$ in length and

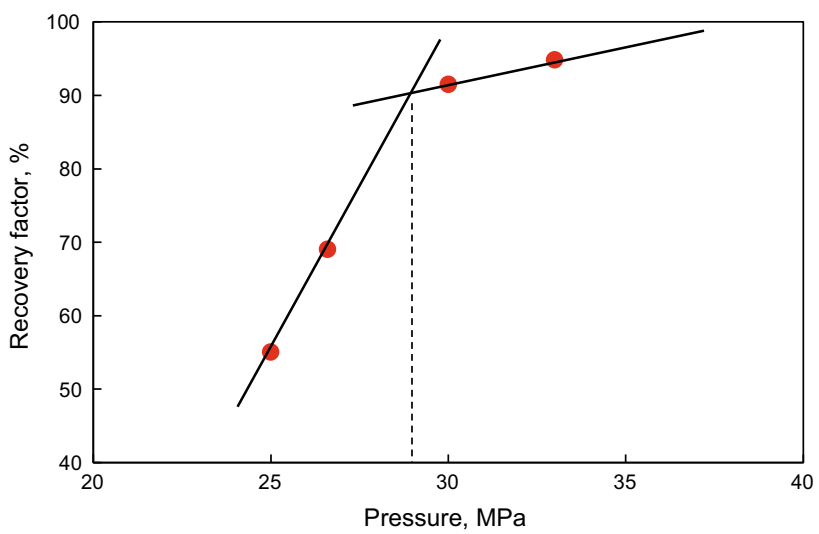

Fig. 4 Observed recovery factor versus different experimental pressures

$2.5 \mathrm{~cm}$ in diameter with a pore volume of $71.6 \mathrm{~cm}^{3}$, while the corresponding average porosity, average permeability, and rock compressibility were determined to be $21.95 \%$, $39.35 \times 10^{-3} \mu \mathrm{m}^{2}$, and $5.2 \times 10^{-6} \mathrm{MPa}^{-1}$, respectively. The brine was composed of $\mathrm{NaHCO}_{3}$ and distilled water with a salinity of $4664 \mathrm{mg} / \mathrm{L}$. Oil samples and hydrocarbon gas injected were the same as those used in the phase behavior studies. Figure 5 presents the schematic diagram of the WAG coreflood experiment. The core sample holder had one inlet located in the left side and one outlet in the right side. The production was performed at a constant outlet pressure, and the injection was performed at a constant surface injection rate. In this displacement experiment, the initial oil saturation, residual oil saturation of the water-oil system, critical gas saturation, and the residual oil saturation of the oil-gas system were accurately measured to be $0.60,0.44,0$, and 0.40 , respectively.

Based on the measured MMP, an immiscible WAG coreflood experiment was carried out under the reservoir temperature of $120.8^{\circ} \mathrm{C}$ and a backpressure of $27 \mathrm{MPa}$. The production performance, such as pressure drop, displacement efficiency, water cut, and cumulative gas-oil ratio, was simultaneously recorded with the advancing of the displacement. For the water flooding stage, the gas was injected at a constant rate of $0.3 \mathrm{~cm}^{3} / \mathrm{min}$. As the water cut reached $85.7 \%$ at the water flooding stage, WAG injection was initiated with a WAG ratio of 3:1 (0.24 PV water vs. $0.08 \mathrm{PV}$ gas) and with four WAG cycles. Soon afterward, the subsequent water flooding was further carried out. Figures 6 and 7 show the production performance of the immiscible WAG displacement experiment. The recovery efficiency was significantly improved during the immiscible WAG processes. With regard to the four slugs of immiscible WAG injection, it was mainly the second WAG cycle that resulted in the greatest improvement of production performance. 
Table 2 Properties of the actual reservoir core samples

\begin{tabular}{lllll}
\hline Core number & Length, cm & Diameter, cm & Porosity, $\%$ & Absolute permeability, $10^{-3} \mu \mathrm{m}^{2}$ \\
\hline 1 & 6.90 & 2.50 & 17.2 & 70.0 \\
2 & 7.09 & 2.52 & 20.4 & 75.3 \\
3 & 5.65 & 2.51 & 19.7 & 94.7 \\
4 & 5.10 & 2.51 & 21.2 & 49.7 \\
5 & 5.71 & 2.50 & 23.7 & 86.9 \\
6 & 4.05 & 2.52 & 20.0 & 49.5 \\
7 & 5.62 & 2.52 & 22.9 & 62.4 \\
8 & 5.75 & 2.51 & 17.8 & 33.2 \\
9 & 4.65 & 2.52 & 18.3 & 38.6 \\
10 & 5.90 & 2.51 & 21.8 & 98.0 \\
11 & 5.65 & 2.50 & 22.2 & 107.1 \\
12 & 4.76 & 2.50 & 23.4 & 127.0 \\
\hline
\end{tabular}

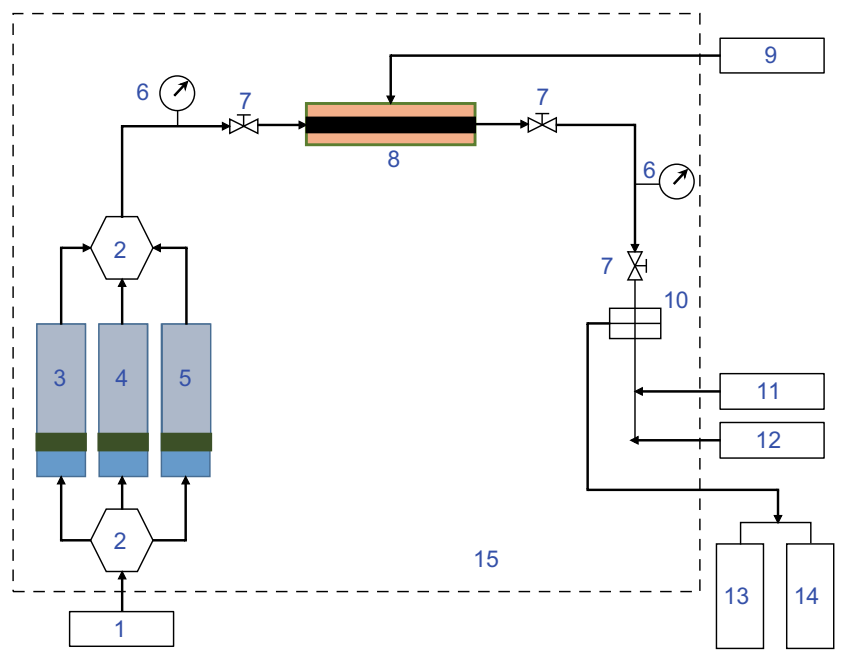

1-Quizix pump
2-Six-way valve
3-Synthetic oil sample
4-Injected hydrocarbon gas
5-Synthetic brine
6-Pressure gauge
7-Two-way valve
8-Core holder
9-Ambient pressure booster pump
10-Backpressure regulator
11-Hand-operated backpressure pump
12-Systematic backpressure pump
13-Liquid meter
14-Gas meter
15-Constant temperature bath

1-Quizix pump

3-Synthetic oil sample

4-Injected hydrocarbon gas

5-Synthetic brine

6-Pressure gauge

7-Two-way valve

Fig. 5 Schematic of the immiscible WAG coreflood experiment system

\section{Estimation of water-oil-gas relative permeability curve}

Considering the above-mentioned immiscible WAG coreflood experiment and history matching results of fluid properties as well as MMP, a one-dimensional compositional model was established using the reservoir simulator CMG. A grid system of $50 \times 1 \times 1$ was selected to represent the physical model in the experiment, resulting in a grid block size of $1.34 \mathrm{~cm} \times 2.23 \mathrm{~cm} \times 2.23 \mathrm{~cm}$. The controlling conditions of compositional simulation were the same as those of laboratory WAG coreflood experiments most widely used. Moreover, the influence of capillary pressure was neglected.

On this basis, the proposed numerical inversion method was employed to interpret coreflood data of the immiscible WAG experiment and to implicitly estimate the water-oilgas relative permeability curve. Figures 8 and 9 display the estimated water-oil and oil-gas relative permeability

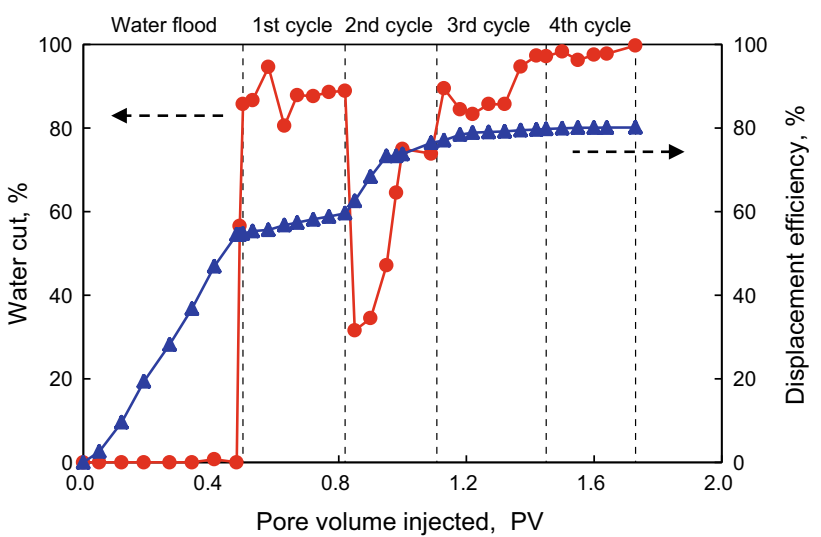

Fig. 6 Variation of the water cut and displacement efficiency during the immiscible WAG processes

curves, respectively, and the dashed lines denote the presumed water-oil and oil-gas relative permeability curves when the iteration was initialized using the LM algorithm 


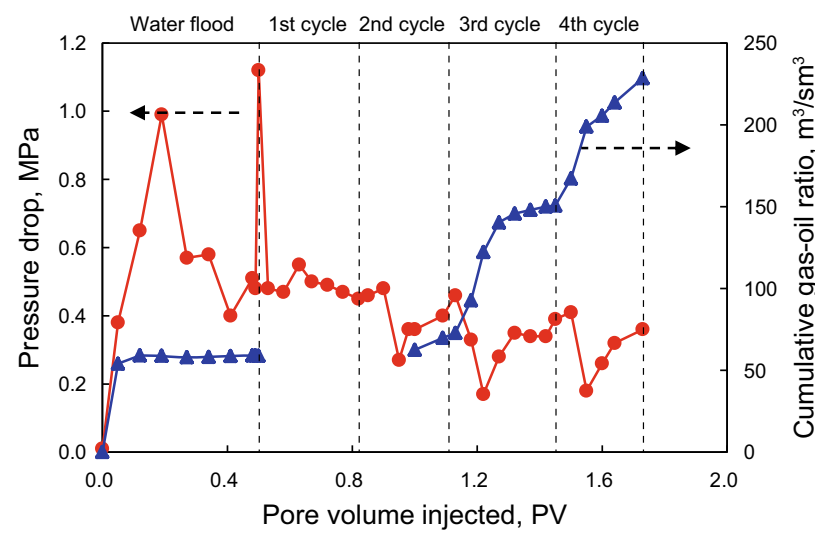

Fig. 7 Variation of the displacement pressure drop and the cumulative gas-oil ratio during the immiscible WAG process

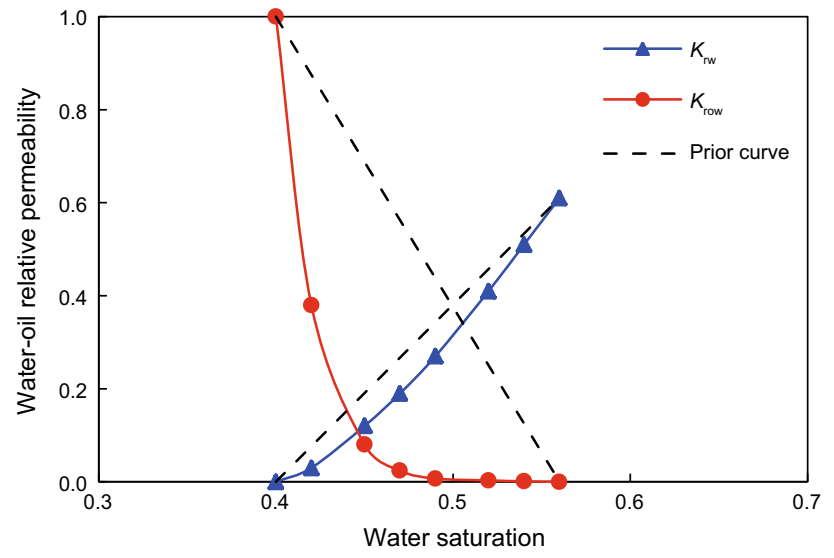

Fig. 8 Estimated water-oil relative permeability curve for the wateroil two-phase system

for automatic history matching. Fitting results of production performance including pressure drop, water cut, and cumulative gas-oil ratio are plotted in Figs. 10 and 11, respectively. To compare the estimation accuracy, Eq. (14) was used to calculate the average absolute error between the predicted result and the observed production data including water cut, pressure drop, and cumulative gas-oil ratio:

$R=\frac{1}{n_{p}} \sum_{i=1}^{n_{p}}\left|\zeta_{i}\right| \quad\left(\zeta_{i}=s_{i}-s_{i}^{\prime}\right)$

where $R$ is the average absolute error; $s_{i}$ is the real value of the $i$ th data point (fraction); $s_{i}^{\prime}$ denotes the estimated value of the $i$ th data point (fraction); $n_{p}$ is the total number of data points; and $\zeta_{i}$ is the absolute error of the $i$ th data point (fraction).

From Figs. 8, 9, 10, and 11, it can be found that the predicted production data including pressure drop, water cut, and cumulative gas-oil ratio are in good agreement with the observed values, with an average absolute error of

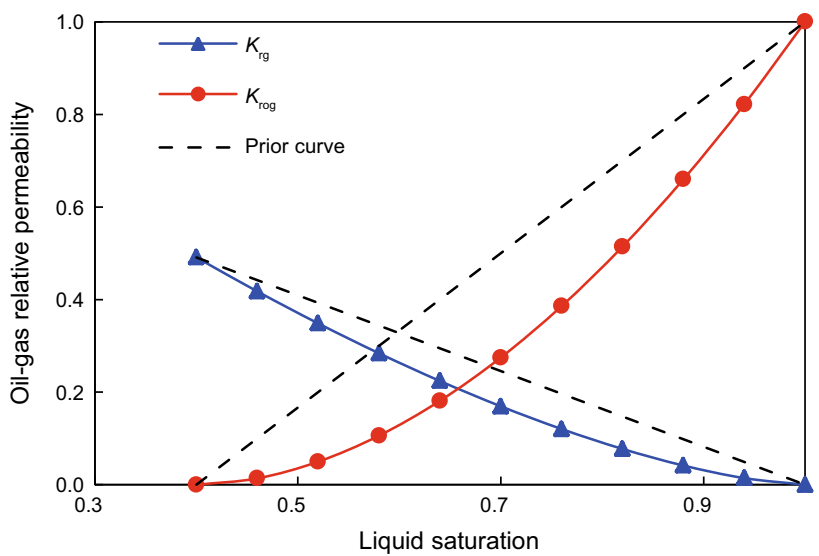

Fig. 9 Estimated oil-gas relative permeability curve for the oil-gas two-phase system

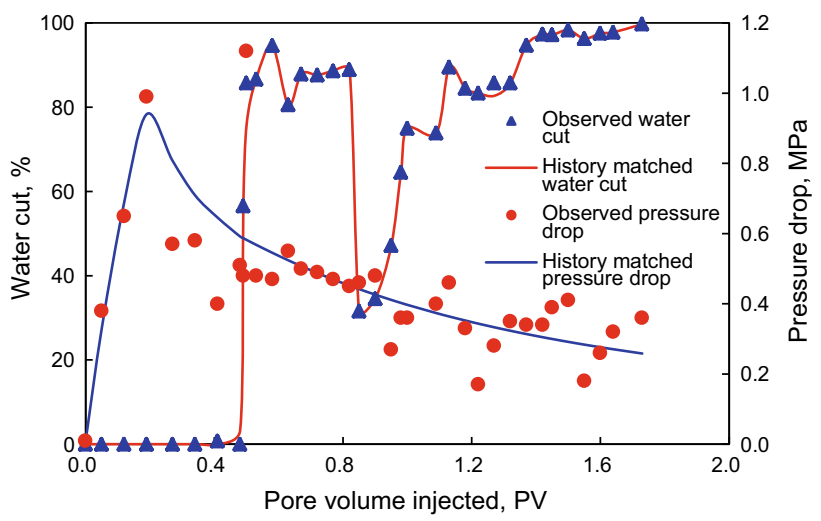

Fig. 10 Fitting results of the observed displacement pressure drop and water cut

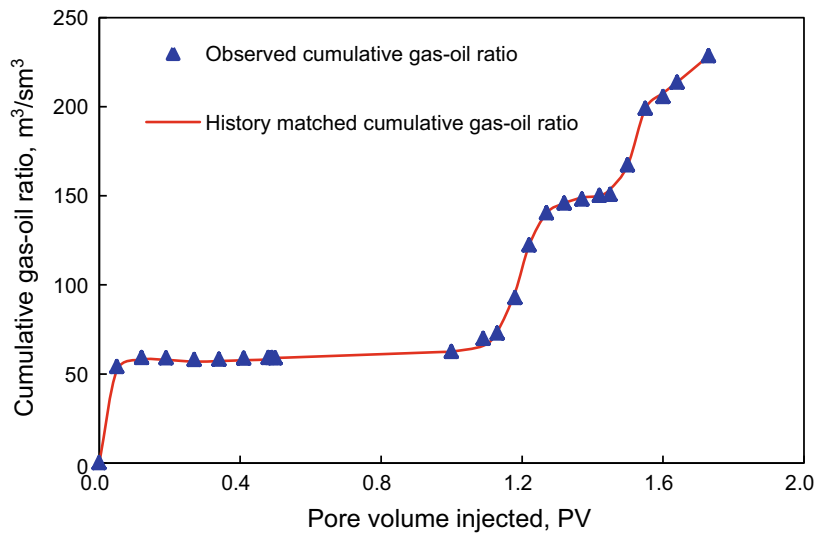

Fig. 11 Fitting results of the observed cumulative gas-oil ratio

$13.6 \%, 2.3 \%$, and $1.7 \%$, respectively, which indicates that the estimated three-phase relative permeability curve is reliable. It also demonstrates that the proposed numerical inversion method is reliable and can meet engineering 
requirements, which provides a basic calculation theory for implicit estimation of water-oil-gas relative permeability curve during immiscible WAG processes.

\section{Conclusions}

(1) The cubic B-spline model (CBM) was used to describe the three-phase permeability curve. The optimization of production performance including pressure drop, water cut, and cumulative gas-oil ratio was performed by adopting the LM algorithm to subsequently adjust the vector of unknown model parameters of the CBM. Finally, a novel numerical inversion method was proposed to implicitly estimate the water-oil-gas relative permeability curves during immiscible WAG flooding processes.

(2) Actual core samples were used for phase behavior studies, MMP measurements, and immiscible WAG coreflood experiments to understand the major recovery mechanisms and thus to generate the fluid properties under reservoir conditions. Based on history matching results of fluid phase behavior and MMP, the proposed method was used to interpret coreflood data from the immiscible WAG experiment in order to implicitly estimate the water-oil-gas relative permeability curve. Results indicate that the proposed method is reliable and can meet engineering requirements. It provides a basic calculation theory for implicit estimation of three-phase relative permeability curve during immiscible WAG processes.

\begin{abstract}
Acknowledgments The authors greatly appreciate the financial support of the Important National Science and Technology Specific Projects of China (Grant No. 2011ZX05010-002), and the Important Science and Technology Specific Projects of PetroChina (Grant No. 2014E-3203).
\end{abstract}

Open Access This article is distributed under the terms of the Creative Commons Attribution 4.0 International License (http://crea tivecommons.org/licenses/by/4.0/), which permits unrestricted use, distribution, and reproduction in any medium, provided you give appropriate credit to the original author(s) and the source, provide a link to the Creative Commons license, and indicate if changes were made.

\section{References}

Abdollahzadeh A, Reynolds A, Christie MA, et al. Estimation of distribution algorithms applied to history matching. In: SPE reservoir simulation symposium, 21-3 Feb, The Woodlands; 2011. doi:10.2118/141161-MS.

Aziz K, Settari A. Petroleum reservoir simulation. Essex: Elsevier Applied Science Publishers; 1979.
Barroeta RG, Thompson LG. Importance of using pressure data while history matching a waterflooding process. In: Trinidad and Tobago energy resources conference, 27-30 June, Port of Spain, Trinidad; 2010. doi:10.2118/132347-MS.

Barua J, Horne RN, Greenstadt JL, et al. Improved estimation algorithms for automated type-curve analysis of well test. SPE Form Eval. 1988;3(1):186-96. doi:10.2118/14255-PA.

Chen BL, Reynolds AC. Ensemble-based optimization of the wateralternating-gas-injection process. In: SPE reservoir simulation symposium, 23-25 Feb, Houston; 2015. doi:10.2118/173217MS.

Chen L, Zhang G, Ge J, et al. Research of the heavy oil displacement mechanism by using alkaline/surfactant flooding system. Colloids Surf A. 2013;434(19):63-71. doi:10.1016/j.colsurfa.2013. 05.035 .

Chen S, Li G, Peres A, et al. A well test for in situ determination of relative permeability curves. SPE Reserv Eval Eng. 2008;11(1): 95-107. doi:10.2118/96414-PA.

Daoud AM, Velasquez LV. 3D field-scale automatic history matching using adjoint sensitivities and generalized travel time inversion. In: SPE annual technical conference and exhibition, 24-27 Sept, San Antonio; 2006. doi:10.2118/101779-MS.

de Boor C. A practical guide to splines. New York: Springer-Verlag; 1978.

Eydinov D, Gao G, Li G, et al. Simultaneous estimation of relative permeability and porosity/permeability fields by history matching production data. J Can Pet Technol. 2009;48(12):13-25. doi:10.2118/132159-PA.

Guo XQ, Yan W, Ma QL. Experimental study of the phase behavior of the reservoir fluid- $\mathrm{CO}_{2}$ system. J Univ Pet China (Ed Nat Sci). 2000;24(3):12-5 (in Chinese).

Han DK. Discussion of concepts, countermeasures, and technical routines for the redevelopment of high water-cut oilfields. Pet Explor Dev. 2010;37(5):583-91 (in Chinese).

Hou J, Wang DG, Luo FQ, et al. Estimation of the water-oil relative permeability curve from radial displacement experiments. Part 1: numerical inversion method. Energy Fuels. 2012a;26(7):4291-9. doi:10.1021/ef300018w.

Hou J, Luo FQ, Wang DG, et al. Estimation of the water-oil relative permeability curve from radial displacement experiments. Part 2: reasonable experimental parameters. Energy Fuels. 2012b;26(7): 4300-9. doi:10.1021/ef3005866.

Hou J, Zhou K, Zhang XS, et al. A review of closed-loop reservoir management. Pet Sci. 2015;12(1):114-28. doi:10.1007/s12182014-0005-6.

Kulkarni KN, Datta-Gupta A. Estimating relative permeability from production data: a streamline approach. SPE J. 2000;5(4):40211. doi:10.2118/66907-PA.

Laochamroonvorapongse R, Kabir CS, Lake LW. Performance assessment of miscible and immiscible water-alternating gas floods with simple tools. J Pet Sci Eng. 2014;122:18-30. doi:10. 1016/j.petrol.2014.08.012.

Lee TY, Seinfeld JH. Estimation of absolute and relative permeabilities in petroleum reservoirs. Inverse Problem. 1987;3(4):71128. doi:10.1088/0266-5611/3/4/015.

Li H, Chen S, Yang D, et al. Estimation of relative permeability by assisted history matching using the ensemble Kalman filter method. In: Canadian international petroleum conference, 16-8 Jun, Calgary; 2009. doi:10.2118/2009-052.

Li H, Chen SN, Yang DY, et al. Estimation of relative permeability by assisted history matching using the ensemble Kalman filter method. J Can Pet Technol. 2012;51(3):1-10. doi:10.2118/ 156027-PA.

Li H, Yang DYT. Estimation of multiple petrophysical parameters for the PUNQ-S3 model using ensemble-based history matching. In: 
SPE EUROPEC/EAGE annual conference and exhibition, 23-26 May, Vienna; 2011. doi:10.2118/143583-MS.

Li Y. Study of enhancing oil recovery of continental reservoirs by water drive technology. Acta Pet Sin. 2009;30(3):396-9 (in Chinese).

Luo P, Zhang YP, Huang S. A promising chemical-augmented WAG process for enhanced heavy oil recovery. Fuel. 2013;104:33341. doi:10.1016/j.fuel.2012.09.070.

Masihi M, Javanbakht L, Bahaloo HF, et al. Experimental investigation and evaluation of three phase relative permeability models. J Pet Sci Eng. 2011;79(1-2):45-53. doi:10.1016/j. petrol.2011.08.017.

Miao TJ, Yu BM, Duan YG, et al. A fractal model for spherical seepage in porous media. Int Commun Heat Mass Transfer. 2014;58:71-8. doi:10.1016/j.icheatmasstransfer.2014.08.023.

Oliver DS, Chen Y. Recent progress on reservoir history matching: a review. Computational Geosciences. 2011;15(1):185-221. doi:10.1007/s10596-010-9194-2.

Reynolds PC, Li R, Oliver DS. Simultaneous estimation of absolute and relative permeability by automatic history matching of threephase flow production data. J Can Pet Technol. 2004;43(3):3746. doi:10.2118/04-03-03.

Salehi MM, Safarzadeh MA, Sahraei E, et al. Comparison of oil removal in surfactant alternating gas with water alternating gas, water flooding and gas flooding in secondary oil recovery process. J Pet Sci Eng. 2014;120:86-93. doi:10.1016/j.petrol. 2014.05.017.

Sheng JJ. Enhanced oil recovery in shale reservoirs by gas injection. Journal of Natural Gas Science and Engineering. 2015;2:252-9. doi:10.1016/j.jngse.2014.12.002.

Sigmund PM, McCaffery FG. An improved unsteady-state procedure for determining the relative-permeability characteristics of heterogeneous porous media. SPE Journal. 1979;19(1):15-28. doi:10.2118/6720-PA.

Wang YD, Li GM, Reynolds AC. Estimation of depths of fluid contacts and relative permeability curves by history matching using iterative ensemble Kalman smoothers. SPE Journal. 2010;15(2):509-25. doi:10.2118/119056-PA.

Wang YD, Li M. Reservoir history matching and inversion using an iterative ensemble Kalman filter with covariance localization. Pet Sci. 2011;8(3):316-27. doi:10.1007/s12182-011-0148-7.

Xu P, Qiu SX, Yu BM, et al. Prediction of relative permeability in unsaturated porous media with a fractal approach. Int $\mathrm{J}$ Heat Mass Transf. 2013;64:829-37. doi:10.1016/j.ijheatmasstransfer. 2013.05.003.

Zhang Y, Yang DY. Simultaneous estimation of relative permeability and capillary pressure for tight formations using ensemble-based history matching method. Comput Fluids. 2013;71:446-60. doi:10.1016/j.compfluid.2012.11.013. 